\title{
OBSERVAÇÃO DE AULAS EM CONTEXTO DE ADD: FUNÇÃO CLASSIFICATÓRIA OU EMANCIPATÓRIA DA CLASSE DOCENTE?
}

\author{
Paula Arnaud Dias*
}

\begin{abstract}
RESUMO: Com a crescente complexidade da sociedade atual novos desafios e funções são pedidos às escolas e estas necessitam de desenvolver no seu interior modelos de supervisão colaborativa que promovam uma cultura de trabalho reflexivo e dialogante. Através desta ação e atitude estaremos a estimular o desenvolvimento da autonomia dos docentes e da organização escolar visando a construção de um ensino e de uma escola de qualidade. É dentro deste quadro de referência que surge a observação de aulas no âmbito da avaliação de desempenho $(A D D)$ e fomos investigar de que forma o processo foi implementado e "vivido" em duas escolas onde exercemos a função de avaliadora e avaliada. Nesse sentido, foram analisadas as grelhas de observação de aulas e ouvidos os seus atores educativos (avaliadores e avaliados) relativamente ao impacto que a observação de aulas teve no seu desenvolvimento/crescimento profissional e da organização educativa no seu todo.

Pretendeu-se investigar se o processo de observação de aulas, nestas duas organizações, foi monitorizado segundo um modelo de supervisão escolar reflexivo e integrado num projeto de escola ou se apenas se limitou a um mero ato administrativo, burocrático e de avaliação sumativa. Toda a investigação teve como finalidade dar resposta à questão que norteou todo o nosso trabalho: Observação de aulas em contexto de ADD: função classificatória ou emancipatória da classe docente?
\end{abstract}

Palavras-chave: Supervisão pedagógica; supervisão escolar; supervisão clínica; observação de aulas; avaliação do desempenho; supervisor; professor reflexivo; dimensão formativa; dimensão sumativa; mudança; escola aprendente.

\section{INTRODUÇÃO}

\footnotetext{
* Professora do QE (grupo 510). Mestre em Ciências da Educação - Especialização em Administração e Organização Escolar (UCP) e formação especializada em Inspeção da Educação e em Supervisão Pedagógica e Avaliação de Docentes (UCP).
} 
Com a massificação e democratização do ensino, a escola dos nossos dias tornou-se num local de maior complexidade e de grande heterogeneidade de alunos. Assim, novas competências e responsabilidades são exigidas à escola de hoje, que passam necessariamente pela construção de uma escola de todos e para todos, onde a educação, em particular o ensino e a aprendizagem de qualidade, se tornou ainda mais importante na vida dos indivíduos.

Estas novas "necessidades" da escola de massas vieram exigir novas tarefas e responsabilidades aos professores, com vista à integração de toda a população escolar e à promoção do sucesso educativo de todos e de cada um.

Partindo do princípio de que, para a melhoria da qualidade da escola, é fundamental a ação docente, torna-se particularmente relevante $o$ desenvolvimento profissional do professor, enquanto agente de mudança nesse contexto. Nesta perspetiva, a supervisão pedagógica adquire um papel particularmente relevante, no sentido de ajudar o docente no aperfeiçoamento das suas práticas, valorizando a reflexão sobre a ação e dando ênfase ao caráter formativo da avaliação docente.

É neste processo de supervisão pedagógica e de avaliação do desempenho docente que surge a observação de aulas como mais uma ferramenta poderosíssima ao serviço da melhoria da qualidade do ensino e da mudança na escola.

Esta observação deverá ser desenvolvida segundo um modelo de supervisão clínica uma vez que este é reconhecido como uma estratégia de supervisão com grandes potencialidades formativas e que potencializa o desenvolvimento profissional e organizacional. A supervisão clínica é um processo de observação-reflexão-ação sobre a prática, centrada na resolução de problemas, o que implica uma colaboração estreita entre observadorobservado (Alarcão \& Tavares, 2003).

Assim, a observação de aulas em contexto de ADD, deverá ser implementada segundo um modelo reflexivo de avaliação de docentes e enquadrar-se num projeto de avaliação global da escola que vise o desenvolvimento pessoal e profissional dos docentes, a melhoria do serviço educativo prestado e o reforço do trabalho colaborativo, com vista ao sucesso educativo dos alunos (Reis \& Alves, 2009, p. 3910).

$\mathrm{O}$ presente trabalho pretendeu analisar de que forma o processo de observação de aulas, no âmbito da avaliação de desempenho docente, foi monitorizado em duas escolas (Escola A e B) onde fomos parte integrante no processo de avaliação de docentes (desenvolvendo a função de avaliadora e avaliada).

Nesse sentido, foram analisadas as grelhas de observação de aulas utilizadas no processo de observação e essa análise foi articulada com os testemunhos dos professores (avaliadores e avaliados) que foram parte integrante de todo o processo avaliativo.

Pretendeu-se investigar qual foi a atitude e envolvimento dos avaliadoresprofessores observados durante o processo de ADD e qual foi a importância 
do ciclo de observações para o processo de supervisão escolar e profissional dos professores. A supervisão tem como finalidade melhorar as práticas e promover a mudança da qualidade de ensino, da aprendizagem e das escolas, bem como potencializar uma relação interpessoal dinâmica, ou seja, um processo partilhado e de abertura à mudança. Este novo conceito de supervisão não se coaduna à imagem de supervisor que possui uma posição dominante e com o total poder de decisão (Graça et al., 2010, p.56).

É necessário que o ciclo de observação de aulas no âmbito da ADD seja desenvolvido segundo um processo colaborativo, dinâmico, reflexivo entre supervisor-professor observado de forma a produzir benefícios a nível de desenvolvimento pessoal e profissional para ambos os intervenientes do processo. "A colaboração nas diferentes fases do processo facilita o estabelecimento de um clima de confiança mútua, sinceridade e respeito, clima esse decisivo para a concretização das potencialidades formativas da observação de aulas" (Reis, 2011, p. 19).

\section{Observação de aulas em contexto de ADD: que finalidades?}

Estamos conscientes que a escola de hoje está sujeita a novas exigências e desafios e assim o conceito de supervisão distanciou-se bastante da sua formulação inicial (formação inicial de professores), adquirindo uma importância fulcral no quadro da avaliação do desempenho docente, particularmente na observação de aulas.

Segundo Alarcão (2001), a multiplicidade de funções a exercer hoje na escola leva a que a supervisão adquira um novo papel e importância e assim se lhe atribua também a dimensão coletiva. De acordo com esta conceção a supervisão não está só associada à sala de aula, mas a toda a escola, não só aos professores isoladamente, mas aos professores na dinâmica das suas interações entre si e com outros e na responsabilidade pelo ensino, formação, educação, valores que praticam (idem, 2001, p. 18). A mesma autora considera que o objetivo da supervisão é o "desenvolvimento qualitativo da organização escola e dos que nela realizam o seu trabalho de estudar, ensinar ou apoiar a função educativa através de aprendizagens individuais e coletivas, incluindo a formação de novos agentes" (idem, 2001, pp.18 - 19).

A observação de aulas em contexto de avaliação de desempenho deve ser enquadrada num Projeto de Escola. Deve recorrer aos referentes externos que lhe conferem legitimidade normativa e conceptual mas, também, invocar os referentes internos que permitem a autenticidade do dispositivo educativo e o respeito pela identidade da Escola (construção coletiva de sentidos para a observação de aulas).

Neste sentido a observação de aulas deve ser parte integrante de uma avaliação que se desenvolva de forma articulada na Escola e incluir várias dimensões do trinómio avaliação: as aprendizagens dos alunos; a organização escolar (autoavaliação de escolas); o desempenho do docente. Todas estas 
dimensões devem ser condicionadas pelos mesmos referentes internos e enquadradas num ciclo de supervisão pedagógica (Reis \& Alves, 2009, pp. 3910 - 3912).

Segundo Vieira \& Moreira (2011), a expressão supervisão pedagógica é definida como “ (...) teoria e prática de regulação de processos de ensino e de aprendizagem sendo o foco de atenção a sala de aula, podendo reportar-se a situações de autos-supervisão e supervisão acompanhada em qualquer cenário de desenvolvimento profissional, incluindo o da avaliação de desempenho" (idem, 2011, p.11). As autoras defendem o recurso ao modelo de supervisão clínica, como estratégia de supervisão e desenvolvimento profissional sempre que a centralidade da observação é o espaço de sala de aula. Pelo exposto a observação de aulas surge como uma estratégia de formação, por excelência, assumindo um caráter essencialmente formativo e regulador dentro do processo de desenvolvimento curricular da Escola, "a avaliação de desempenho, materializada num ciclo de observações, não fica refém do livre arbítrio dos seus atores, mas indexada a referentes contextuais, internos, que estabelecem o enquadramento da avaliação em torno de princípios e valores subjacentes à conceção dos referenciais internos para a observação" (idem, 2009, p.3912).

Segundo (Goldharmmer et al., 1980, citados por Vieira e Moreira, 2011, p. 29) a supervisão clínica apresenta dimensões e caraterísticas importantes para observação de aulas e nesse sentido deverá: ser orientada por finalidades e combinar necessidades individuais coletivas de desenvolvimento profissional; supor uma relação de trabalho entre supervisor e professor que requer confiança mútua, traduzida em compreensão, apoio e comprometimento nos processos de desenvolvimento profissional; ser sistemática, embora requeira uma flexibilização e atualização constante da sua metodologia; gerar uma tensão positiva no sentido de ultrapassar o desfasamento entre o real e o ideal; pressupor que o supervisor saiba mais do que o professor acerca da instrução e da aprendizagem e requer a formação do supervisor.

Segundo Graça et al., (2010) a avaliação de desempenho pode ser encarada como um processo contínuo de acompanhamento do trabalho dos professores, promover o seu desenvolvimento profissional e identificar áreas em que a formação contínua deve incidir. As escolas ao desenvolverem esta atividade de avaliação dos seus profissionais estão a criar condições que lhes permitem alcançar, de forma mais efetiva, os seus objetivos, de acordo com as suas caraterísticas e com as necessidades dos seus alunos. Assim, as escolas, antes de darem início ao seu processo de avaliação, deverão construir, internamente, os seus referenciais e indicadores de desempenho, adequando-os à sua especificidade, à tipologia dos seus discentes e aos objetivos que se propõe alcançar.

Segundo os mesmos autores existem três objetivos para que se desenvolva o processo de avaliação de desempenho: desenvolvimento profissional (a ADD fornece à escola informações sobre os seus professores 
permitindo também que estes identifiquem as suas potencialidades e áreas que necessitam de melhorar, contribuindo desta forma para a melhoria da qualidade da escola); responsabilização (através da definição de padrões de desempenho, é possível identificar as boas práticas bem como aquelas que carecem de melhoria. Desta forma as escolas poderão desencadear estratégias de melhoria onde todos os professores são corresponsabilizados pela otimização e sucesso das mesmas); motivação (fornecer aos professores o feedback construtivo sobre o seu desempenho, verificando-se que este procedimento estimula o desenvolvimento da qualidade dos professores) (idem, 2010, p.21).

É dentro deste quadro de avaliação de desempenho que surge a estratégia de observação de aulas, concebida como uma estratégia privilegiada de formação de professores e de crescimento organizacional. Assim, e de acordo com o quadro normativo que a sustenta, deverão as escolas desenvolver no seu interior os mecanismos que lhes permitam analisar/interpretar/adaptar/contextualizar essas linhas orientadoras/legislativas às suas necessidades específicas enquanto organização, “(...) a observação de aulas enquadrar-se-á num projeto global de escola e contribuirá para o desenvolvimento pessoal e profissional do docente, para a melhoria do serviço educativo prestado e para o incremento do trabalho colaborativo, com vista ao sucesso educativo dos alunos" (Reis \& Alves, 2009, p. 3910).

Acreditamos que a observação e a discussão de aulas por um supervisor, poderá ter um papel determinante na melhoria da ação educativa e um impacto positivo no desenvolvimento profissional de professores, ao permitir-lhes potencializar competências metacognitivas, nomeadamente conhecer, analisar, avaliar e questionar a sua prática docente - criação de contextos de supervisão colaborativa. Segundo Cruz (2009), na supervisão colaborativa, ambos os sujeitos (avaliador e avaliado) são professores comprometidos com a autorreflexão das práticas de ensino e de aprendizagem reais e na implementação de experiências conducentes à resolução dos problemas diagnosticados. Assim, a observação de aulas só tem sentido e uma função social e profissional se promover o aparecimento de novas ideias sobre o ensino, e se permitir desenvolver um ambiente de abertura, confronto, diálogo e cumplicidade entre professores (Cruz, 2009, pp. 137-139).

O avaliador/relator deverá ser responsável pelo acompanhamento e supervisão do processo de desenvolvimento profissional do avaliado, com o qual deve manter uma interação permanente no sentido de potencializar e otimizar a dimensão formativa da avaliação do desempenho docente (Graça et al, 2010, pp. $58-59$ )

Segundo Reis (2011), a observação desempenha um papel determinante na melhoria da qualidade do ensino e da aprendizagem, constituindo-se uma fonte de inspiração e motivação e um forte catalisador de mudança na escola. 
A observação de aulas surge como um processo essencialmente formativo/colaborativo e contextualizado às necessidades do seu público-alvo - professores e alunos. Apresentam-se algumas das finalidades da observação de aulas propostas por Reis (2010, p.11):

- Diagnosticar os aspetos /as dimensões do conhecimento e da prática profissional a trabalhar/melhorar;

- Adequar o processo de supervisão às caraterísticas e necessidades específicas de cada professor;

- Estabelecer as bases para uma tomada de decisão fundamentada sobre o processo de ensino e aprendizagem;

- Avaliar a adequação das decisões curriculares efetuadas pelos professores e, eventualmente, suscitar abordagens ou percursos alternativos;

- Proporcionar o contacto e a reflexão sobre as potencialidades e limitações de diferentes abordagens, estratégias, metodologias e atividades;

- Desenvolver diferentes dimensões do conhecimento profissional dos professores.

Cruz (2009, p. 141 - 142) refere que a utilidade da observação de aulas reside fundamentalmente no contributo que daí advém para a auto-avaliação do trabalho do professor (observador e observado). Assim, a observação de aulas deverá ser uma estratégia que os professores utilizam para recolher elementos da sua atuação em contexto de sala de aula e com base nos dados recolhidos desencadear a reflexão critica sobre a ação (entre supervisor e observado). Por sua vez o supervisor deverá assumir "o papel de promotor de desenvolvimento das capacidades de auto-reflexão num contexto interpessoal construtivo" (idem, 2009, p.142).

Por último, e referenciando novamente Reis (2011, pp. 11 - 19), a observação de aulas deverá ser um processo: de interação profissional e essencialmente formativo; que visa o desenvolvimento individual e coletivo dos professores; que potencializa a melhoria da qualidade de ensino e das aprendizagens; colaborativo e diferenciado (de acordo com as necessidades do professor); que promove a criação de comunidades de aprendizagem dentro da escola; continuado e contextualizado de desenvolvimento pessoal e organizacional; colaborativo entre supervisor-professor (que promova o desenvolvimento pessoal e profissional de ambos).

\section{Tipos de observação de aulas: informal e formal}

A observação de aulas, independentemente da tipologia utilizada (informal ou formal) visa compreender e analisar as estratégias e metodologias de ensino utilizadas, as atividades educativas implementadas, as interações professor-aluno, diagnosticar um problema, encontrar e testar possíveis soluções para o problema, entre outras. 
As observações de carater informal definem-se por visitas de curta duração (podem oscilar entre 15 a 20 min e cerca de 2 min) onde o supervisor entra e sai da sala de aula sem aviso prévio e sem utilizar grelhas de observação. Segundo vários autores, e como refere Reis (2011, pp. 13 - 14), o método de Downey walk-through (visitas de cerca 2-3 min.), apresenta um impacto positivo em termos educacionais e tem como objetivo principal promover o crescimento profissional do observado. Nesse sentido, o supervisor deverá formular uma questão de debate e/ou comentário que estimule no professor a reflexão sobre as suas práticas, potencializando desta forma a predisposição para a melhoria e para o crescimento profissional do observado. Todas as visitas, independentemente da sua duração e do método supervisivo utilizado, deverão ser complementadas com uma reunião de discussão sobre os aspetos observados e suas inferências para futuras ações educativa e melhoria do serviço educativo prestado.

Reis (2011, p. 14), apresenta uma listagem com algumas orientações para a observação informal de aulas, destacando-se as seguintes ideias: todos os professores beneficiam da observação informal das suas aulas, logo deverá ser uma prática a privilegiar com frequência e com consistência ao longo da sua carreira. Nestas visitas é importante estabelecer um foco de observação que assegure a obtenção de informações ricas e relevantes, apesar da brevidade das visitas. Todas estas observações deverão ser complementadas com o fornecimento do feedback por parte do supervisor. Nesse sentido deverão ser realizadas reuniões de trabalho entre supervisor-professor com o objetivo de refletirem em conjunto sobre a observação efetuada e estimular futuras observações. "A qualidade das questões para reflexão, as sugestões e os comentários apresentados têm um impacto decisivo no grau de reflexão e de desenvolvimento profissional suscitado" (Reis, 2011, p.14).

As observações formais, requerem outro tipo de preparação e de planeamento para a sua concretização e são fortemente influenciadas pelo método de supervisão clínica (observação-reflexão-ação, sobre a prática profissional em contexto de sala de aula) o que envolve a repetição cíclica de uma sequência de fases (pré-observação, observação e pós-observação). A observação de aulas surge como uma estratégia supervisiva colaborativa entre supervisor-professor durante as três fases do processo e representando benefícios mútuos para ambos os intervenientes: potencializar o desenvolvimento pessoal e profissional - enfoque nas dimensões formativas da observação de aulas.

Segundo vários autores, destacando Reis (2011) e Vieira \& Moreira (2011) o ciclo de observações é constituído por três etapas que se apresentam de forma resumida:

1) Pré-observação: negociação das regras para a observação; selecionar /adaptar instrumentos de observação (global ou focalizada); análise e discussão do plano de aula (com 
caracterização/especificidades da turma); motivar o professor para a observação (postura pró-ativa/reflexiva).

2) Observação: recolha de informação de acordo com os focos específicos a observar (definidos com o professor); seleção das metodologias a utilizar (registos descritivos/interpretativos); seleção /conceção dos instrumentos de recolha de dados a utilizar (grelhas de observação, listas de verificação, escalas de classificação, mapas de registos).

3) Pós-observação: analisar os dados recolhidos e registados durante a observação; refletir sobre o significado dos dados recolhidos; fornecer feedback construtivo que vise o desenvolvimento pessoal e profissional do professor; definir prioridades para as próximas observações; negociar metas de aprendizagem e de melhoria das práticas (construção de sentidos).

Consideramos que o processo de observação de aulas só terá um impacto positivo e renovador no processo de crescimento pessoal e organizacional se todos os atores educativos e lideranças em geral the reconhecerem validade $\mathrm{e}$ carater formativo, contextualizando-o às necessidades e especificidades de cada organização educativa - ser parte integrante das suas metodologias de supervisão organizacional.

Segundo Reis (2011) "a observação de aulas deverá sempre integrar-se num processo continuado e contextualizado de desenvolvimento pessoal e organizacional, orientado por ideias claras e explícitas sobre o ensino e a aprendizagem" (idem, p.17).

\section{Supervisor e professor observado: funções e competências}

De acordo com o Decreto Regulamentar no 2/2010 de 23 de junho, é ao avaliador/relator que cabe a função de supervisão de toda a atividade docente, nomeadamente a responsabilidade última sobre o processo de avaliação de docentes.

Segundo Wiles \& Bondi (2000, citados por Graça et al., 2010, p. 57) para o exercício das funções supervisivas é necessário que o supervisor/relator tenha conhecimentos nessa área de especialidade, bem como possua competências que se relacionam com a tomada de decisões e de gestão, o planeamento e a monitorização das atividades, as competências de investigação, realçando também as competências de formação pessoal bem como a capacidade para a discussão e aconselhamento resultantes de todo o processo supervisivo. Considera-se que cabe ao avaliador/relator incentivar a mudança e a melhoria da prática, ajudando a diagnosticar a realidade e a ultrapassar eventuais problemas, sempre segundo uma perspetiva de corresponsabilidade e de interajuda, informando, questionando, sugerindo, avaliando, encorajando o professor que está a ser observado.

Segundo Reis (2011, p. 17), o supervisor desempenha um papel de modelo e assim deverá possuir competências ao nível da vertente pessoal 
(relação interpessoal e de comunicação) e ao nível da vertente profissional (forte credibilidade como profissional e capacidade de saber ouvir, encorajar, organizar, acompanhar todo o processo supervisivo).

Apresentam-se de seguida algumas das funções a desempenhar pelo supervisor durante o ciclo de observação de aulas, apresentadas por Reis (2011, p. 20):

\section{1-Pré-observação}

- Clarificar os objetivos da observação;

- Reunião com o professor no sentido de discutir os objetivos da aula, estratégias a utilizar para concretizar esses objetivos, a integração da aula a observar no currículo e planificação da disciplina, as propostas de diferenciação previstas tendo por base as caraterísticas e ritmos dos alunos, entre outras;

- Discussão sobre os aspetos/dimensões em que o professor gostaria que se centrasse a atenção do supervisor;

- Explicitação, por parte do supervisor do que irá fazer durante a observação;

- Definição/marcação de uma data e hora para a reunião de feedback.

\section{2-Durante a observação}

- O supervisor deverá ser um agente que não perturbe a aula (reduzir o impacto da sua presença e só participar se for solicitada a sua intervenção);

- Registar as observações de acordo com as grelhas previamente estabelecidas;

- Registar as suas impressões e questões sobre aspetos que quer abordar com o observado (registos devidamente documentados e contextualizados) na reunião de feedback.

\section{3-Após a observação}

- Reconstruir, com o professor, o que aconteceu na aula (levar o professor a refletir e apresentar os pontos fortes e fracos da sua aula, bem como as situações atípicas que podem ter ocorrido, no seu entender);

- O supervisor deve ser claro e centrar-se em situações concretas da aula (descrevendo os comportamentos observados em vez de os etiquetar e/ou avaliar);

- A sua intervenção nesta fase do processo deverá ter sempre presente os comportamentos observados e os que considera que o professor observado tem a capacidade e a possibilidade de os modificar;

- Apresentar sugestões construtivas e que potencializem o caracter formativo do ciclo da observação de aulas que supervisionou. 
Por sua vez o professor avaliado deve interagir com o supervisor no sentido de proporcionar evidências sobre o seu desempenho (mostrar evidências pertinentes e relevantes para a sua avaliação) e proceder à sua autoavaliação numa lógica de continuidade e de melhoria progressiva do seu desempenho. "Nesse sentido, o professor avaliado deve observar e analisar o seu desempenho, numa perspetiva de professor reflexivo que constrói os significados da sua prática, identificando os seus pontos fortes, para os poder partilhar, e reconhecendo os seus pontos fracos, para procurar estratégias de superação e solução, entre as quais, a formação que conduza ao seu desenvolvimento profissional" (Graça et al., 2010, p. 58).

Segundo Reis (2011, p. 20) as funções a desempenhar pelo professor, durante o ciclo de avaliação, são as seguintes:

\section{1-Pré-observação}

- Preparar-se para a reunião com o supervisor no sentido de discutir as regras de observação, os objetivos da aula, estratégias a utilizar para concretizar esses objetivos, a integração da aula a observar no currículo e planificação da disciplina, as propostas de diferenciação previstas tendo por base as caraterísticas e ritmos dos alunos, entre outras;

- Discussão sobre os aspetos/dimensões em que gostaria que se centrasse a atenção do supervisor;

- Informar o supervisor sobre o local onde gostaria que ele se sentasse, bem como o tipo de intervenção que este poderá ter na aula.

\section{2-Durante a observação}

- Apresentar o supervisor aos alunos, explicando o objetivo da sua presença na sala de aula;

- Logo após terminar a aula o professor deverá anotar as suas reflexões sobre a forma como esta decorreu no sentido de poder discutir de forma consistente e fundamentada a observação da mesma com o supervisor.

\section{3-Após a observação}

- Reconstruir, com o supervisor, o que aconteceu na aula (refletir e apresentar os pontos fortes e fracos da sua aula, bem como as situações atípicas que podem ter ocorrido, no seu entender);

- Solicitar comentários e sugestões construtivas sobre aspetos específicos.

\section{Análise das grelhas de observação de aulas em contexto de ADD}

Na nossa investigação foram objeto de análise as grelhas de observação utilizadas no âmbito da Avaliação de Desempenho Docente (ADD), em duas escolas A e B, onde desenvolvemos a atividade de avaliadora e avaliada. É de referir que os dados apresentados resultaram: da nossa experiência como avaliadora e avaliada; da análise documental dos instrumentos utilizados nas duas organizações; de conversas formais e informais com a comunidade 
docente nas escolas A e B (avaliadores/relatores e avaliados de ambas as escolas).

As grelhas de observação de aulas (Escola A e B) constituem os anexos I e II respetivamente.

Apresentam-se de seguida as tabelas 1 e 2 que pretendem apresentar de forma clara e objetiva os dados resultantes da nossa análise reflexiva e crítica dessa ferramenta de trabalho - grelhas de observação de aulas, evidenciando também os pontos fortes e fracos que estas apresentam, na nossa opinião. É de referir ainda que a análise dos pontos fortes e fracos das grelhas de observação de aulas foi feita no seu todo (Escola A e B simultaneamente) uma vez que se verificou que, apesar do seu aspeto formal ser algo diferente, apresentam a mesma linha/orientação no tocante à sua constituição/formulação de dados e orientações metodológicas.

Caraterização da amostra nas Escolas A e B:

Escola $\mathrm{A}-8$ avaliadores/relatores e 15 avaliados;

Escola B - 6 avaliadores/relatores e 6 avaliados.

\section{Quadro I}

Apresentação dos resultados resultantes da análise das grelhas de observação

\begin{tabular}{|c|c|}
\hline \multicolumn{2}{|c|}{ Análise das grelhas de observação de aulas } \\
\hline Escola A & Escola B \\
\hline $\begin{array}{l}\text { - Aspeto gráfico funcional e de fácil } \\
\text { preenchimento; } \\
\text { - Documento estruturado de forma a } \\
\text { reduzir a subjetividade do avaliador } \\
\text { (Dimensões-Domínios-Indicadores- } \\
\text { Instrumentalização-Observações); } \\
\text { - O referencial de avaliação está construído } \\
\text { em torno de três domínios (não explicita } \\
\text { o B4. Processo de avaliação das } \\
\text { aprendizagens dos alunos); } \\
\text { - A cada domínio está associado um ou } \\
\text { mais indicadores que materializam a } \\
\text { excelência do desempenho docente } \\
\text { (Despacho no } 160347 / 2010 \text { ); } \\
\text { - Os indicadores são objetivos, curtos e } \\
\text { claros. Salienta-se a presença/clarificação, } \\
\text { sempre que necessária, da explicitação do } \\
\text { indicador (entre parêntese e de forma } \\
\text { exemplificativa); } \\
\text { - Apresenta um espaço organizado para a } \\
\text { análise/reflexão descritiva da aula (pontos } \\
\text { fortes-aspetos a melhorar-sugestões e } \\
\text { recomendações). }\end{array}$ & $\begin{array}{l}\text { - Aspeto gráfico funcional e de fácil } \\
\text { preenchimento; } \\
\text { - Documento estruturado de forma a } \\
\text { reduzir a subjetividade do avaliador } \\
\text { (Dimensões-Domínios-Critérios- } \\
\text { Indicadores-Instrumentalização- } \\
\text { Observações); } \\
\text { - O referencial de avaliação está } \\
\text { construído em torno dos quatro } \\
\text { domínios; } \\
\text { - Cada domínio possui um ou mais } \\
\text { critérios de avaliação (recurso a palavras } \\
\text { chave/adjetivação); } \\
\text { - A cada critério está associado um ou } \\
\text { mais indicadores que materializam a } \\
\text { excelência do desempenho docente } \\
\text { (Despacho no 160347/2010); } \\
\text { - Os indicadores são objetivos estão } \\
\text { definidos a partir de uma frase clara e } \\
\text { curta que os explicita; } \\
\text { - Apresenta um espaço organizado para a } \\
\text { análise/reflexão descritiva da aula } \\
\text { (pontos fortes-pontos a melhorar- } \\
\text { capacidade de reflexão e de melhoria da }\end{array}$ \\
\hline
\end{tabular}


sua prática).

\section{Quadro II}

Apresentação dos pontos fortes e fracos presentes nas grelhas de observação

Análise das grelhas de observação de aulas (Escola A e B)

\section{Pontos fortes}

- Apresentam uma estrutura simples, clara e de fácil preenchimento;

- Apresentam indicadores objetivos e pouco "colados", em termos de escrita, aos textos complexos presentes nos normativos que implementam a ADD;

- Preocupação de reduzir a subjetividade da avaliação feita pelo avaliador (indicadores claros, simples e objetivos e observ. real em contexto de sala de aula);

- Apresentam uma estrutura que permite também o registo descritivo, reflexão e fundamentação no preenchimento da grelha da observação;

- Possuem um espaço para reflexão e evidência fundamentada, dos pontos fortes e dos que carecem de melhoria, bem como promover no avaliado a reflexão sobre a reorganização e melhoria de todo o processo.

\section{Pontos fracos/a melhorar}

- Não apresentam na sua estrutura os focos de observação, bem como questões orientadoras para a sua observação e registo;

- Apresentam apenas as dimensões impostas pelos normativos legais - fator redutor num processo de supervisão e crescimento profissional;

- Grelhas fechadas no tocante à avaliação de outras observações pertinentes (observ. focada e/ou circunstancial) e com valor pedagógico vivenciadas na aula observada;

- Construção da grelha não de acordo com as finalidades/propósitos de uma avaliação formativa..."valor formativo questionável";

- Grelhas coladas aos parâmetros de avaliação de desempenho- reduz o carater formativo da observação.

\section{Considerações finais sobre o processo de observação de aulas investigado: perceções dos intervenientes...}

Foi nosso interesse investigativo auscultar as opiniões e "estados de alma" dos intervenientes (avaliadores e avaliados) em todo o processo de preparação, implementação e conclusão deste ciclo avaliativo em contexto de ADD. Em ambas as escolas o processo foi calendarizado e dado a conhecer a toda a comunidade docente.

Para a construção das grelhas de observação de aulas, em ambos os casos, foi solicitada a opinião dos professores e nesse sentido estes documentos foram analisados em reuniões de Departamento Curricular. Todas as opiniões e fundamentações dos professores foram transmitidas pelos coordenadores, verificando-se que os documentos finais apenas refletiam a opinião e sugestões da Comissão de Coordenação da Avaliação de Desempenho (CCAD). O ciclo de observações foi totalmente implementado, em termos de reuniões, conforme explicitam os normativos legais (antes-durante-após as observações de aula). Os documentos utilizados em ambas as escolas, foram quase na generalidade dos casos, preenchidos pelos avaliadores e dados a conhecer aos avaliados - perguntando: "concordas com a tua avaliação?". 
Nesse sentido não houve a preocupação, na grande maioria dos casos de partilhar, analisar, clarificar, fundamentar os registos apresentados nas grelhas de observação. Verificou-se da observação das grelhas, após o seu preenchimento, que os campos de análise descritiva e reflexiva, quando preenchidos, revelavam pouco empenho e reflexão no sentido da supervisão e melhoria das práticas letivas. Também nestes casos não foram discutidos e explicitados aos avaliados os registos efetuados pelos avaliadores - processo estanque e redutor (fechado sobre si próprio).

Tal como foi referido pela quase totalidade dos professores, só em situações muito pontuais é que houve a preocupação de fornecer ao avaliado, na reunião pós-observação, o feedback construtivo no sentido da sua melhoria e/ou otimização e diversificação das suas potencialidades pedagógicas - caráter formativo da avaliação. Referiram que estas situações só foram vividas em casos muito especiais/excecionais onde avaliador e avaliado já se conheciam há muito tempo e existia uma grande cumplicidade de trabalho para além do facto de os observados reconhecerem mérito e grande profissionalismo ao seu avaliador.

Pelo exposto considera-se que nas Escolas A e B As lideranças e comunidade docente em geral não reconheceram, ao processo de ADD, vantagens e valor acrescentado no tocante à valorização e melhoria da organização escolar e das suas práticas pedagógicas/desenvolvimento profissional. Referiram/interiorizaram que todo o processo não teve qualquer conteúdo/valor formativo, considerando que se regeu segundo uma visão instrumentalista da avaliação e ao serviço de uma máquina administrativa e burocrática da organização-estado (processo com caráter meramente administrativo e com a finalidade de dar cumprimento a um normativo legal).

Verbalizaram também que se tratou de um processo gerador de conflitos "implícitos" e "explícitos" dentro destas comunidades escolares, onde o professor observado teve um papel passivo e a observação de aulas (duas) foi um ato isolado de avaliação sumativa, determinante para a avaliação de desempenho do professor e não como mais uma etapa dentro do ciclo de observação desse docente (consideram que todo o processo foi monitorizado segundo uma dimensão meramente sumativa, estandardizada e punitiva juízo de valor - atribuição de níveis de desempenho).

\section{Que papel desempenhou a observação de aulas em contexto de ADD? Função classificatória ou emancipatória?}

Após termos sido investigadores ativos e parte integrante no processo de observação de aulas nas duas escolas que foram objeto de estudo, consideramos que todo o processo foi conduzido e implementado segundo uma função meramente classificatória.

Esta inferência resulta da nossa convicção de que apenas houve a preocupação por parte das lideranças de topo e intermédias de articular 
esforços e sinergias no sentido de operacionalizar e "dar rosto" a mais um normativo emanado da tutela. Os professores (avaliadores e avaliados) e lideranças tiveram a preocupação de operacionalizar com rigor todas as etapas do processo (reuniões de pré-observação, observação e pósobservação) e dar a conhecer os documentos e calendarização que sustentavam a observação de aulas - processo meramente sumativo e avaliativo com repercussões no percurso/graduação dos docentes - carater subjetivo e punitivo. Stronge (2010), citando Bacharach, et alii, refere que a avaliação de desempenho docente está frequentemente reduzida a uma função meramente burocrática, geradora de conflitos e mal-estar entre os professores e direções das escolas, que acabam por levar à desconfiança mútua, comprometendo assim todo o processo e desvirtuando a função última da avaliação: o incremento da melhoria e da qualidade (idem, 2010, pp. 29 30).

Consideramos que o processo de observação de aulas foi redutor, contextualizado apenas à observação de duas aulas, "fechado sobre si próprio" pois todos os agentes educativos não lhe reconheceram validade e com potencialidades para desencadear, no interior de cada organização, um processo de supervisão formativa e de melhoria da organização e da ação educativa prestada pelos seus profissionais.

Segundo Alarcão \& Tavares (2003) é fundamental que o clima de desconfiança, associado às estratégias supervisivas, dê lugar a uma relação de supervisão da prática educativa, onde a auto e heterossupervisão participadas e comprometidas entre os professores permitam, contribuir para o crescimento e melhoria da sua atividade de ensino e educação, numa escola que, também ela se encontra num processo de desenvolvimento e aprendizagem. Assim, e segundo Reis (2011) a observação de aulas surgirá como um processo de interação profissional e constituir-se-á como parte integrante de um processo continuado e contextualizado de desenvolvimento pessoal e organizacional. Todo este processo deverá ser alicerçado em ideias claras e explícitas sobre o ensino e a aprendizagem, sendo desta forma um pilar estruturante para a discussão e a melhoria das práticas dos professores (idem, 2011, pp. 11 - 17).

Assim, e a partir da nossa observação participada e testemunhos recolhidos, somos levados a concluir que as dimensões de supervisão pedagógica e colaborativa, a melhoria da ação educativa, a construção coletiva de sentidos para a observação de aulas, o crescimento organizacional, entre outras, não foram potencializados e operacionalizados neste processo de observação de aulas no âmbito da ADD. 


\section{CONCLUSÃO}

Ao refletirmos sobre o desenvolvimento do processo de avaliação de desempenho docente, tal como decorreu nos nossos contextos escolares, somos levados a concluir, antes de mais, que o peso da dimensão sumativa e do caráter burocrático da avaliação é ainda muito evidente.

Porém, parece-nos que, apesar de regulado pelos mesmos normativos, o processo de avaliação docente fica, por vezes, "ao sabor" das perceções e sensibilidades de cada liderança organizativa, sendo contextualizado de formas diferentes.

Consideramos, que o caráter formativo e de crescimento/valorização profissional deveriam ser a tónica de um processo que se quer dinâmico, promotor da reflexão e partilha de experiências educativas.

Para tal é necessário tempo, acompanhamento/supervisão pedagógica e implicação direta dos professores. Estes deverão sentir-se implicados e reconhecer mérito e competência técnico-pedagógica a quem acompanha todo o processo.

Para isso, é importante a constituição de um corpo de professores especializados que possam acompanhar, numa cultura colaborativa, o processo de avaliação de desempenho docente, numa perspetiva de melhoria.

A observação de aulas surgirá como mais um elemento de supervisão pedagógica onde a implicação dos intervenientes é determinante para o sucesso do processo. Este envolvimento e atitude pró-ativa passará também pela reflexão, experimentação, reconstrução dos próprios instrumentos supervisivos que se querem claros, diversificados (grelhas abertas, registos descritivos e interpretativos, grelhas de verificação, entre outras), contextualizados e que reflitam as "observações em ação".

Pensamos que é necessária uma calendarização mais alongada e supervisionada do processo de avaliação docente, permitindo a reflexão e o desenvolvimento profissional que os normativos preconizam.

Assim, concluímos que o profissionalismo docente e a autonomia da classe passam, necessariamente, pela supervisão pedagógica, enquanto especialização docente que permite um melhor acompanhamento, contribuindo, portanto, para o desenvolvimento profissional de avaliador e avaliado.

Nesse sentido a observação de aulas no âmbito da ADD, poderá surgir como uma função emancipatória da classe docente... Para tal é necessário que a organização a reconheça como um contributo para o seu crescimento e processo de mudança. Nesse sentido deverá ser enquadrada no projeto/identidade da Escola e no seu processo de autonomia.

Por último, a comunidade docente deverá reconhecer-lhe valor acrescentado, e percecionar a observação de aulas como mais um elemento a monitorizar no processo de supervisão pedagógica dos professores e organização escolar - escola aprendente e dialógica. 
Existirá um longo caminho a desenvolver... Fica o desafio...

\section{BIBLIOGRAFIA}

Alarcão, I. (2001). Escola reflexiva e Supervisão. Uma escola em desenvolvimento e aprendizagem. Porto: Porto Editora.

Alarcão, I. \& Tavares, J. (2003). Supervisão da Prática Pedagógica. Uma perspetiva de desenvolvimento e aprendizagem. Coimbra: Livraria Almedina. $2^{\mathrm{a}}$ ed.

Cruz, Isabel M. (2009). Observação de Aulas: Estratégias de Desenvolvimento Profissional. Revista ELO 16, pp. 137-145.

Formosinho, J. O. (2002). A Supervisão na formação de professores I - Da sala à Escola. Porto Editora, pp. 166 - 237.

Formosinho, J. O. (2002). A Supervisão na formação de professores II - Da Organização à Pessoa. Porto Editora, pp. 134 - 194.

Graça, A. et al., (2010). Avaliação de Desempenho Docente. Lisboa Editores.

Reis, Paulo M. J. \& Alves, Maria P. C. (2009). Observação de Aulas em Contexto de ADD: um projeto de escola à procura dos referentes. Atas do $\mathrm{X}$ Congresso Internacional Galego-português de Psicopedagogia. Braga: Universidade do Minho, pp. 3910 - 3923.

Reis, Pedro (2011). Observação de aulas e avaliação do desempenho docente. Ministério da Educação-Conselho Cientifico para a Avaliação de Professores. Caderno do CCAP-2.

Silva, H. S. \& Loureiro, A. (2010). A supervisão: funções e competências do supervisor. EDUSER: Revista de Educação, Vol. 2(1), pp. 37 - 51.

Stronge, James H. (2010). A Avaliação de professores numa perspetiva internacional. Capítulo I $O$ que funciona, de facto, na avaliação de professores: Breves considerações, pp. 24 - 43. Coleção Saberes Plurais.

Vieira, F. \& Moreira, M. A. (2011). Supervisão e avaliação do desempenho docente - para uma abordagem de orientação transformadora. Ministério da Educação - Conselho Cientifico para a Avaliação de Professores. Caderno do $\mathrm{CCAP}-1$.

\section{Legislação Consultada:}

Decreto Regulamentar n ${ }^{\circ}$ 26/2012 de 21 de fevereiro

Decreto Regulamentar no 2/2010 de 23 de junho

Decreto-Lei 41/2012, de 21 de fevereiro

Decreto-Lei 75/2010, de 23 de junho

Decreto-Lei 270/2009, de 30 de setembro 